\title{
The Potential for an Impending Sea-Level Rise
}

Sarah K. McLeod ${ }^{*}$

Grant MacEwan University, Canada

\begin{abstract}
Sea level rise has become one of the most discussed topics regarding climate change. In the past the sea level has been known to rise several meters during interglacial periods. The rapid spread of human populations and new technological innovations have led to an outpouring of carbon dioxide over the centuries causing the global mean temperature to rise by $0.8^{\circ} \mathrm{C}$. This slight increase in temperature has raised sea level from thermal expansion of the ocean and is having a dramatic effect on the cryosphere. Retreating glaciers continue to contribute to the current rate of sea level rise but the potential for the Greenland and Antarctic ice sheets to melt from increasing global temperatures could raise the ocean by more than $1 \mathrm{~m}$ this century. Low-lying developing countries such as Bangladesh and Vietnam are the most vulnerable to a rise in sea level due to lack of infrastructure, high population densities, and geographic locations situated on a delta. In the developed world, Australia and Italy are at risk areas due to large populations found along the coast in both countries. If the rate of mass loss from glaciers and ice sheets continue a future sea level rise is imminent.
\end{abstract}

\section{Introduction}

Sea level rise has surfaced as one of the most intensely studied and discussed aspects of climate change in recent years. The mean global temperature has increased by $0.8^{\circ} \mathrm{C}$ 
in the last century and according to the Intergovernmental Panel on Climate Change (IPCC) the mean global temperature is expected to continue increasing at a more rapid rate (Kump et al., 2010, p. 323). Until recently, thermal expansion of seawater from increased temperatures has been the most significant source of sea level rise (Richardson et al., 2011, p. 51) at a rate of $1.6 \mathrm{~mm} /$ year (Curtis and Schneider, 2011, p. 31). However, the rapid melt water run-off from terrestrial and land locked glaciers into the oceans as stated by Barry (2006) is raising sea level by 15-20\% (p. 285) or $3.1 \mathrm{~mm} /$ year (Curtis \& Schneider, 2011, p. 31). If current mass loss continues, glaciers have the potential to raise sea level by $40 \mathrm{~cm}$ (Kump et al., 2010, p. 322) this century.

The contribution from glaciers is minimal when compared to the massive amounts of ice stored in the polar ice sheets. Evidence from the Earth's last interglacial period, the Eemian, suggests both the Greenland and Antarctic ice sheets have had significant contributions to sea level rise of about 6 to $9 \mathrm{~m}$ (Richardson et al., 2011, p. 58). The IPCC uses past climate scenarios to help predict rates of future sea level rise and the effect that the melting of the polar ice sheets would have on countries around the world. Currently, the projected best-case scenario by the IPCC is for sea levels to rise by less than $0.59 \mathrm{~m}$ by the year 2100 (Curtis \& Schneider, 2011, p. 31). If the ocean were to rise by $0.5 \mathrm{~m}$, it is estimated that $10 \%$ of the global population, over 650 million people, would be directly impacted (Richardson et al., 2011, p. 66). Many lowland developing countries would be at risk from flooding, storm surges, loss of land and loss of life. The projected maximum sea level rise for the $21^{\text {st }}$ century is about $2 \mathrm{~m}$ (p. 63). Yet if Greenland and Antarctica were to melt entirely, eustatic sea levels could climb by $7 \mathrm{~m}$ and $70 \mathrm{~m}$ respectively (Kump et al., 2010, p. 323). Predicting the outcome of the interconnected earth system remains very much a guessing game, which makes it imperative that nations prepare for worst-case scenarios. This report will discuss the current systems in place contributing to sea level rise, the predicted impact of future contributions from the diminishing Greenland and Antarctic ice sheets, and how it would impact low-lying developing countries as well as developed countries.

\section{Results}

With global temperatures continuing to increase, terrestrial glaciers are the major contributing factor to eustatic sea level rise this century. The strongest mass loss has been seen in Canada, Alaska, and Patagonia. Between 2005 and 2009, the Canadian Arctic archipelagos (Fig. 1) experienced some of the warmest summer temperatures on record (Gardner et al., 2011, p. 357). It was discovered by Gardner et al. (2011) that a one degree Kelvin rise in mean surface air temperature results in an additional 64 gigatons, with a gigaton being 1000000000 metric tons, of ice lost to the oceans (p. 
359). Similarly, in the Gulf of Alaska, glaciers lost mass at an average rate of $88 \mathrm{Gt} /$ year $^{-1}$. Glaciers around the globe are retreating at an alarming rate with the East African Mountains expected to have no ice remaining within two to three decades and the loss of ice mass has doubled in the Patagonian ice fields (Barry, 2006, p. 286) to a rate of 28 Gt/year ${ }^{-1}$ (Gardner et al., 2011, p. 359). If the current rate of glacial mass loss continues, sea level could rise by $40 \mathrm{~cm}$ (Kump et al., 2010, p. 323) this century. Predicting how much the ocean will rise in the future has been a controversial issue, however, it is fully understood that terrestrial glaciers are contributing to sea level rise. It is not well understood to what extent the polar ice caps of Greenland and Antarctica are contributing to sea levels.

The Greenland ice sheet covers almost $80 \%$ of total land area in Greenland and contains enough water to raise sea level by 7m (Kump et al., 2010, p. $324)$ if it were to melt completely. The average

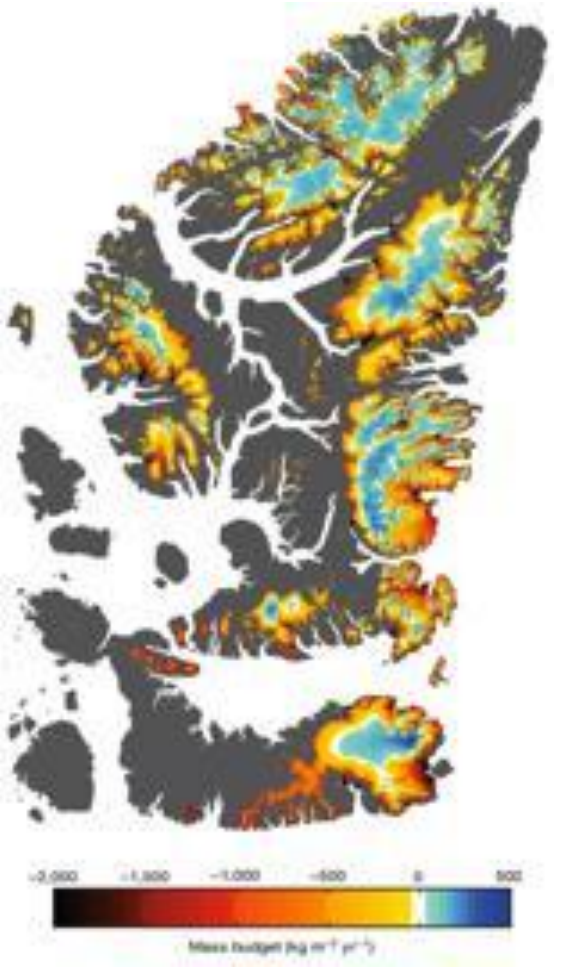

Fig. 1. Surface mass budget of the northern Canadian Arctic Archipelago from 2003 to 2009. Emphasizing the extreme mass loss at outlets of glaciers as indicated in black (Gardner et al. 2011). global temperature has increased by $0.8^{\circ} \mathrm{C}$ in the last century. The Arctic is experiencing an increase that is twice the global average; in effect the Greenland ice sheet is experiencing a more rapid decline (Fig. 2) than the Antarctic ice sheet (Richardson et al., 2011, p. 169). Due to lower latitudes and warmer temperatures the melt season has increased by 50 days and the ice sheet is losing volume at a rate of $200 \mathrm{Gt} /$ year $^{-1}$ (p. 169). Consequently, this is a substantial difference from the $74 \mathrm{Gt} /$ year $^{-1}$ the ice sheet was losing between 1997 and 2003 that the IPCC Third Assessment used in determining the Greenland ice sheet contributions to sea level rise (Dasgupta et al., 2008, p. 3). If the current rate of melting continues, the Greenland ice sheet could contribute to a $50 \mathrm{~cm}$ global sea level rise (Richardson et al., 2011, p. 169) by the end of the century. 


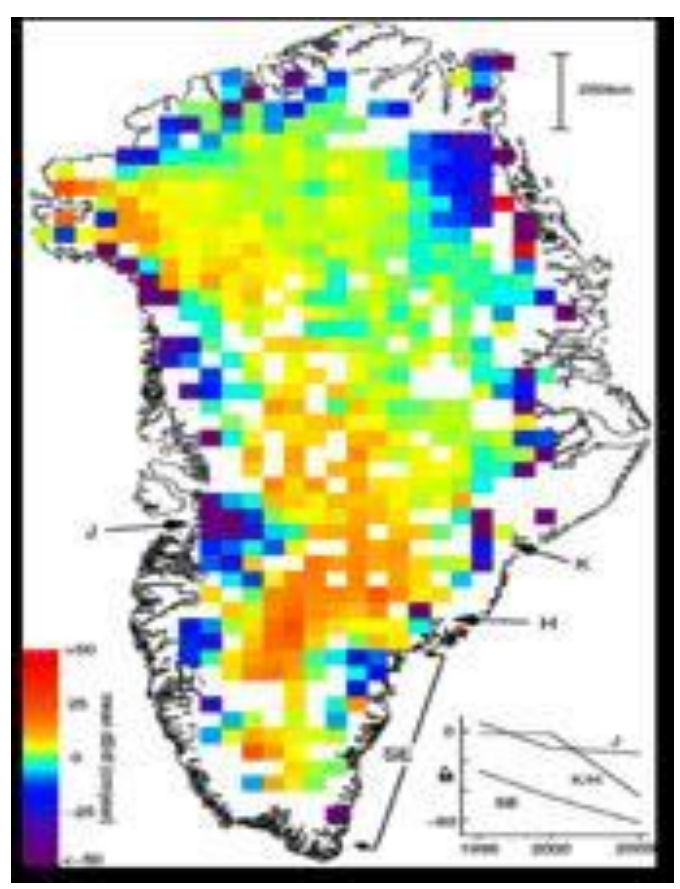

Fig. 2. Elevation changes from altimeter measurements on the Greenland ice sheet. Rapid thinning is seen at outlet glaciers J, $\mathrm{H}$ and $\mathrm{K}$ (Lemke

Accurate measurements are vital in predicting future ocean levels. Since the IPCC have recognized the importance ice caps could have on sea level rise, there has been a push for advancements in technological surveying equipment. A new coastal database has been developed that is specifically designed to address the vulnerabilities and the needs of coastal areas under sea level rise scenarios (Vafeidis et al., 2008, p. 922). Advancements in altimetry, which measures altitude, and interferometry, which measures incoming electromagnetic waves, have allowed researchers to obtain more accurate measurements on the distribution of snow fall, mass imbalance and the rate of retreat (Shepard \& Winghamz, 2007 , p. 1) ice caps are experiencing. Satellite imaging from the Gravity Recovery and Climate Experiment, or GRACE has also been a major contributor in providing visual proof of rapid ice mass loss in Greenland and Antarctica (Richardson et al., 2011, p. 59). Antarctica remains one of the most difficult areas to study in the world due to its climate and location but could have the most substantial effect on sea level rise.

The Antarctic continent contains the world's largest amount of frozen fresh water (Gomez et al., 2010, p. 623). Experts agree that if global warming were to surpass $4^{\circ} \mathrm{C}$ (Richardson et al., 2011, p. 170) the Antarctic ice sheets would melt causing the ocean to rise by 60 to 70 meters (Kump et al., 2010, p. 323). Fortunately, global temperatures have not exceeded $4^{\circ} \mathrm{C}$, but the present $0.8^{\circ} \mathrm{C}$ increase in the last hundred years is having a noticeable impact in Antarctica. Sections of the Larsen Ice Shelf in the Antarctica Peninsula have thinned and collapsed (Shepard \& Winghamz, 2007, p. 1). The breakup of the Larson A and Larson B ice shelves in 1995 and 2002 respectively, have accelerated glacier flow into the ocean (Jakobsson et al., 2010, p. 691). The Pine Island Glacier has retreated up to $1.2 \mathrm{~km} /$ year $^{-1}$ and is thinning at a rate of about $1.6 \mathrm{~m} /$ year $^{-1}$ (Shepard \& Winghamz, 2007, p. 1). This glacier is considered to be highly unstable because it has punched through the ice shelves contributing to nearly 30\% of ice drainage from the West Antarctic ice sheet (Jakobsson et al., 2010, p. 691). Drainage of melt water into the 
oceans may be accelerated by blue ice that is found in Antarctica. Blue ice normally has large ice grains and low albedo that can accelerate melt water by almost 30 times the rate of snow melt (Liston \& Winther, 2005, p. 1479). The current rate of melting is not evenly distributed on the Antarctic continent and the ice sheets are divided into two regions, the East and West Antarctic ice sheets.

The West Antarctic Ice Sheet, or WAIS, has the potential to raise sea levels by $8.4 \mathrm{~m}$ (Gomez et al., 2010, p. 629). Measurements from the Global Positioning System have raised concerns that surface melt water is increasing in flow velocity and penetrating through to the bedrock, accelerating ice flow to the ocean when the WAIS is already losing mass at about $50 \mathrm{Gt} /$ year $^{-1}$ (Shepard \& Winghamz, 2007, p. 1). The WAIS is unique because two thirds of it rests on bedrock below sea level, which makes it prone to more rapid melting from warming ocean temperatures (Richardson et al., 2011, p. 64). Scientists fear that as the ocean warms, the WAIS might collapse under its own weight from losing mass beneath the surface, causing the collapse of the ice shelves (p. 66) that support the WAIS, which could lead to a free-floating ice sheet. Ice sheets have a gravitational pull on the surrounding ocean, but as fresh water enters the ocean there is a build-up of water close to the ice mass which reverses the cycle and restricts the water from dispersing (Gomez et al., 2010, p. 624) and speeds up melting under the ice sheet. This cycle is known as a fingerprint (Douglas, 2008, p. 218) and is important in aiding scientists to accurately predict future sea level rise. Estimates are that if the WAIS

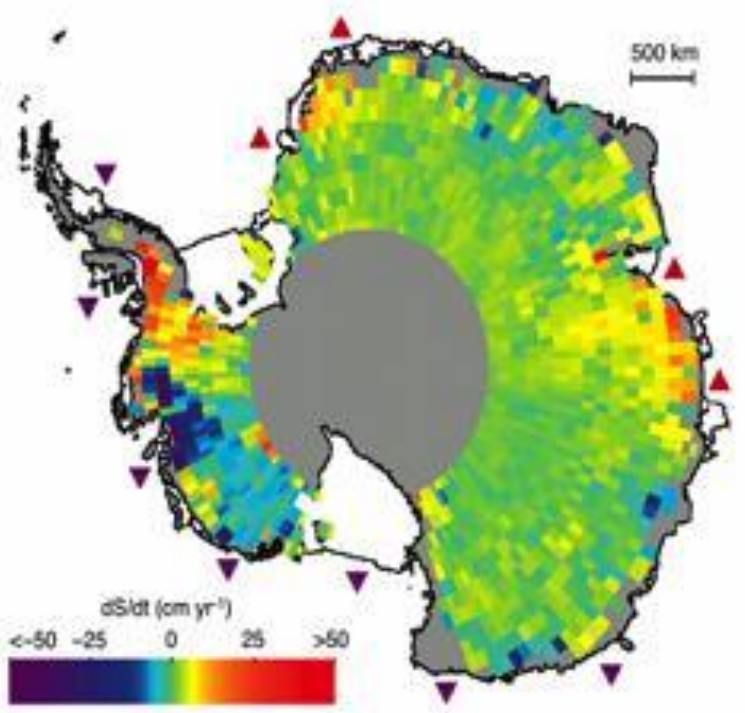

Fig. 3. Elevation changes from altimeter measurements over Antarctic ice sheet. Ice shelves may be thickening or thinning (Lemke and Ren 2007). continues to recede at its current rate, it would contribute up to $60 \mathrm{~cm}$ (Richardson et al., 2011, p. 170) of eustatic sea level rise during this century. This contribution, however, would be minor in comparison to the East Antarctica Ice Sheet.

The East Antarctica Ice Sheet, or EAIS, is much larger than the WAIS and contains the largest reservoir of ice in the world with the potential to raise the ocean by $18 \mathrm{~m}$ (Gomez et al., 2010, p. 629). The EAIS is actually gaining in mass from increased snowfall (Fig. 3) because warmer oceans increase evaporation rates. The ice sheet is 
expected to thicken for the next 50 to 100 years (Kump et al., 2010, p. 323) at a rate of 25 Gt/year ${ }^{-1}$ (Shepard \& Winghamz, 2007, p. 1). The EAIS gaining ice mass may help to decrease the rate of sea level rise from increasing temperatures, but it will ultimately fall short when the mass loss of other regions is taken into consideration (Kump et al., 2010, p. 323). Although most of the EAIS is growing, it is important to note that there are two glaciers in East Antarctica (Shepard \& Winghamz, 2007, p. 1) that are losing mass. The potential threat of rising sea levels is a global concern because every country on Earth would be directly or indirectly affected by it.

\section{Discussion}

Even a slight change in sea level will have an immediate effect on the thirty-three countries that have land below sea level. Developing countries are especially at risk because of their lower adaptive capacity (Richardson et al., 2011, p. 67). Bangladesh is one of the most vulnerable (Ward, 2010, p. 155) with almost half of its land area less than $8 \mathrm{~m}$ above sea level. Bangladesh is situated on a large delta that is prone to flooding caused by monsoons, glacier run off from the Himalayas, and severe storm surges from cyclones. Some experts predict that a $20 \mathrm{~cm}$ increase in sea level in the Bay of Bengal will displace almost 10 million people in Bangladesh and effectively $20 \%$ of the land area would be underwater (p. 156). This increase does not include areas that would be affected by storm surges and salt contamination of freshwater. Historically, storms and floods have had a devastating impact on human lives in the country. Unlike developed nations, Bangladesh has not constructed any infrastructure like dams or dikes to counter the threat of a rising ocean and they do not intend to (p. 226). The unprotected coast and high level of poverty in Bangladesh will only worsen the problem as sea levels rise.

According to a study done by Dasgupta et al. (2009), East Asia (Fig. 4) would be the most severely impacted region in the developing world with respect to sea level rise ( $\mathrm{p}$. 16). Dasgupta et al. (2009) compared 84 developing countries that were assessed based on impacts on land area, population, gross domestic product, agriculture, and wetlands ( $\mathrm{p}$. 4). The results put Vietnam as the most impacted country in four out of the five categories. The reason

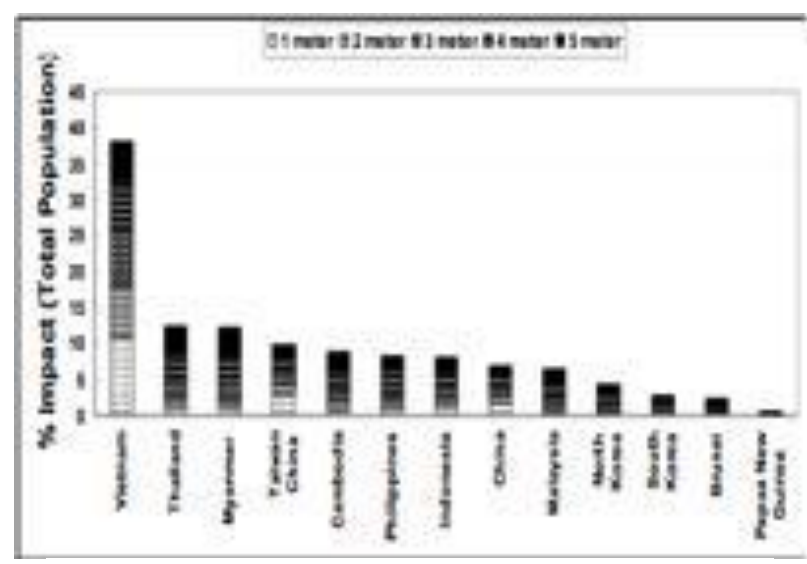

Fig. 4. Percentage of population impacted in East Asia at different levels of sea level rise (Dasgupta et al. 2009). 
Vietnam is so susceptible to ocean levels is similar to why Bangladesh is so vulnerable; the southern half of the country sits on the Mekong and Red River Deltas. A large portion of Vietnam's population and economic activity is found in this region. A $1 \mathrm{~m}$ rise in sea level would impact $10.8 \%$ of the population and $10 \%$ of its GDP.

Although developing countries are more vulnerable to ocean levels, the developed world would not be unaffected by sea level rise. Australia and Italy are considered the most vulnerable of developed countries to sea level rise due to the majority of the population and infrastructure located along the coast (Richardson et al., 2011, p. 67) and as a result governments have heavily invested in planning for adaptation. The Australian Government Department of Climate Change estimates that a sea level rise of more than $1 \mathrm{~m}$ will displace 250000 people from their homes (p. 58). Venice, one of the most iconic cities of the Renaissance in Italy and a United Nations World Heritage Site is at severe risk from changing sea levels. It was built on soft sediment and the heavy buildings are increasing its decline into the seabed. Additionally, the water line in Venice is $25 \mathrm{~cm}$ higher than in 1897 when the reference line was established (Ward, 2010, p. 166). The government has spent more than 15 billion in adaptation plans, most of which has gone to reinforcement of ancient sea walls (Richardson et al., 2011, p. 401) and break waters. Some critics have suggested Venice be abandoned (Ward, 2010, p. 167) as flooding has become more frequent and is beginning to erode the brickwork of the buildings. The loss of such a magnificent city would undoubtedly stand as dramatic evidence for the consequences of sea level rise.

\section{Conclusion}

The ocean is continuing to rise at a more rapid rate than in the previous century. Contributions from the Greenland and Antarctic ice sheets have the potential to raise sea level by several meters. For now, melting ice sheets have not made a significant impact on sea levels unlike the fresh water run-off from terrestrial glaciers. Glaciers are responsible for the current rise in ocean levels that will put many low-lying developing countries at risk to increased flooding and has prompted many developed countries to prepare adaptation plans for oceans that will continue rising over the next century. A rise in the sea level would have devastating consequences, most of which the full extent of is not understood, and may result in the largest displacement of people the world has ever seen. 
*Writer: Sarah K. McLeod is a third year student studying at Grant MacEwan University in Edmonton, Alberta, Canada. With her undergraduate degree she will attain a major in biology and minor in earth and environmental sciences. In January of 2012, she completed a six-week internship in Western Australia assisting the resident Ph.D. student with abundance and habitat modeling of the local bottlenose dolphins that inhabit the bay.

\section{References}

Barry, R.G. 2006. The Status of research on glaciers and global glacier recession: a review. Progress in Physical Geography, 30(3): 285-306.

Curtis, K., and Schneider, A. 2011. Understanding the demographic implications of climate change: estimates of localized population predictions under future scenarios of sea-level rise. Population \& Environment, 33(1): 28-54.

Dasgupta, S., Laplante, B. et al. 2009. The Impact of Sea Level Rise on Developing Countries: A Comparative Analysis. Climate Change, 93(3/4): 379- 388.

Douglas, B.C. 2008. Concerning Evidence for Fingerprints of Glacial Melting. Journal of Coastal Research, 24(2): 218-227.

Gardner, A.S., Moholdt, G., Wouters, B. et al. 2011. Sharply increased mass loss from glaciers and ice caps in the Canadian Arctic Archipelago. Nature, 473(7347): 357360.

Gomez, N., Mitrovica, J.X., and Clark, P.U. 2010. A new projection of sea level change in response to collapse of marine sectors of the Antarctic Ice Sheet. Geophysical Journal International, 180(2): 623-634.

Jakobsson, M., Anderson, J.B., Nitsche, F.O. et al. 2011. Geological record of ice shelf break-up and grounding line retreat, Pine Island Bay, West Antarctica. Geology, 39(7): 691-694.

Kump, L.R., Kasting, J.F, \& Crane, R.G. (2010). The Earth System. Upper Saddle River, New Jersey: Pearson Education.

Lemke, P., and Ren, J. 2007. Observations: Changes in Snow, Ice and Frozen Ground [online]. Intergovernmental Panel on Climate Change Third Assessment: 339-378. 
Available from http://www.ipcc.ch/pdf/assessment-report/ar4/wg1/ar4-wg1chapter4.pdf [accessed 29 November 2011].

Liston, G.E., and Winther, J.G. 2005. Antarctic Surface and Subsurface Snow and Ice Melt Fluxes. Journal of Climate, 18(10): 1469-1481.

Richardson, K., Steffen, W., \& Liverman, D. (2011). Climate Change: Global Risks, Challenges and Decisions. Cambridge, New York: Cambridge University Press.

Sharp, M., and Wang, L. 2009. A Five-Year Record of Summer Melt on Eurasian Arctic Ice Caps. Journal of Climate, 22(1): 133-145.

Shepard, A., and Winghamz, D. 2007. Recent Sea-Level Contributions of the Antarctic and Greenland Ice Sheets. Science, 315(5818): 1529-1532.

Vafeidis, A.T., Nicholls, R.J. et al. 2008. A New Global Coastal Database for Impact and Vulnerability Analysis to Sea-Level Rise. Journal of Coastal Research, 24(4): 917925.

Ward, P.D. (2010). The Flooded Earth: Our Future in a World Without Ice Caps. New York: Basic Books 